\title{
Characteristics on Stand-alone Operation of a Doubly-fed Induction Generator Applied to Adjustable Speed Gas Engine Cogeneration System
}

\author{
Tetsuji Daido ${ }^{\dagger}$, Yushi Miura ${ }^{*}$, Toshifumi Ise ${ }^{*}$, and Yuki Sato ${ }^{* *}$ \\ $\dagger^{* *}$ Graduate School of Engineering, Osaka University, Osaka, Japan \\ ***ergy Technology Laboratory, Osaka Gas Co., Ltd., Osaka, Japan
}

\begin{abstract}
An application of doubly-fed induction generator (DFIG), which is one of adjustable speed generators, to a gas engine cogeneration system has been investigated. . To operate during a blackout as an emergency power supply is one of important roles for the gas engine cogeneration system. However, the DFIG requires initial excitation for startup during a blackout because the DFIG has no excitation source. In this paper, we propose the "blackout start" as a new excitation method to generate a rated voltage at the primary side during a blackout. In addition, a stand-alone operation following a blackout has been investigated by using experimental setup with a real gas engine. Power flows in the generating set with the DFIG at the stand-alone operation have been investigated experimentally. Experimental investigation of the power flow suggests that the generating set with DFIG has optimal speed in minimizing whole system losses.
\end{abstract}

Key words: Blackout start, Doubly-fed induction generator, Gas engine cogeneration system, Power flow, Stand-alone operation

\section{INTRODUCTION}

In recent years, a lot of attention has been paid on cogeneration systems that efficiently utilize natural resources to reduce $\mathrm{CO}_{2}$ emission. A synchronous generator directly connected to loads and a grid has been used for conventional medium-sized gas engine cogeneration systems whose rated power is more than $300 \mathrm{~kW}$. However, the gas engine is restricted in operating at constant speed because of the synchronous generator. Fig. 1 shows the specific fuel consumption (SFC) curves according to the power and speed of the $26 \mathrm{~kW}$ diesel engine [1]. A gas engine has characteristics similar to those of the diesel engine. When the engine operates at constant speed, the efficiency of the gas engine goes down in part-load condition. A gas engine is also incapable of operating in an overloaded condition at constant speed because the output torque of the gas engine reaches its upper limit. Moreover, the

Manuscript received Mar. 14, 2013; revised Jul. 5, 2013

Recommended for publication by Associate Editor Seung-Ho Song.

†Corresponding Author: daido@pe.eei.eng.osaka-u.ac.jp

Tel: +81-6-6879-7691, Osaka University

* Graduate School of Engineering, Osaka University, Japan

${ }^{* *}$ Energy Technology Laboratory, Osaka Gas Co., Ltd., Japan

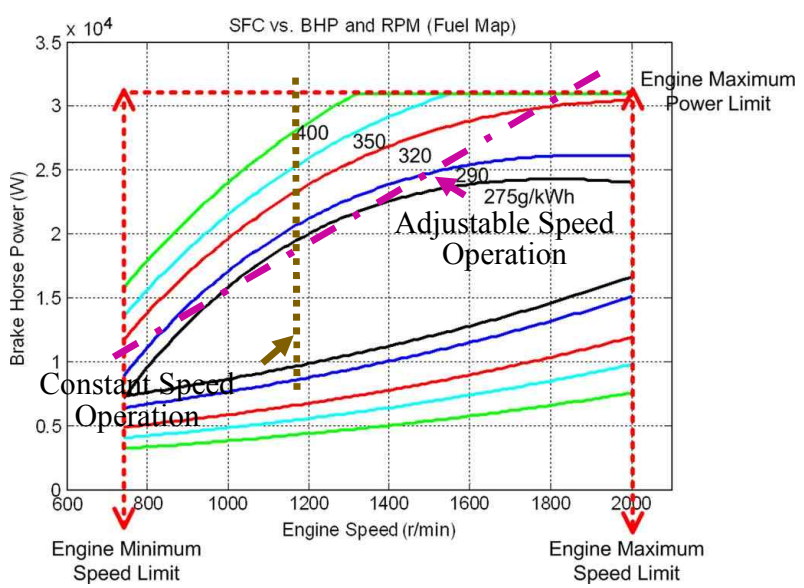

Fig. 1. Specific fuel consumption according to power and speed [1].

gas engine must be developed and tested according to grid frequency because the gas engine driven at synchronous speed is designed to be at the highest efficiency during a rated power operation. Furthermore, in the case of stand-alone operation, the amount of step load input is restricted to making frequency excursion within the allowable frequency range. 


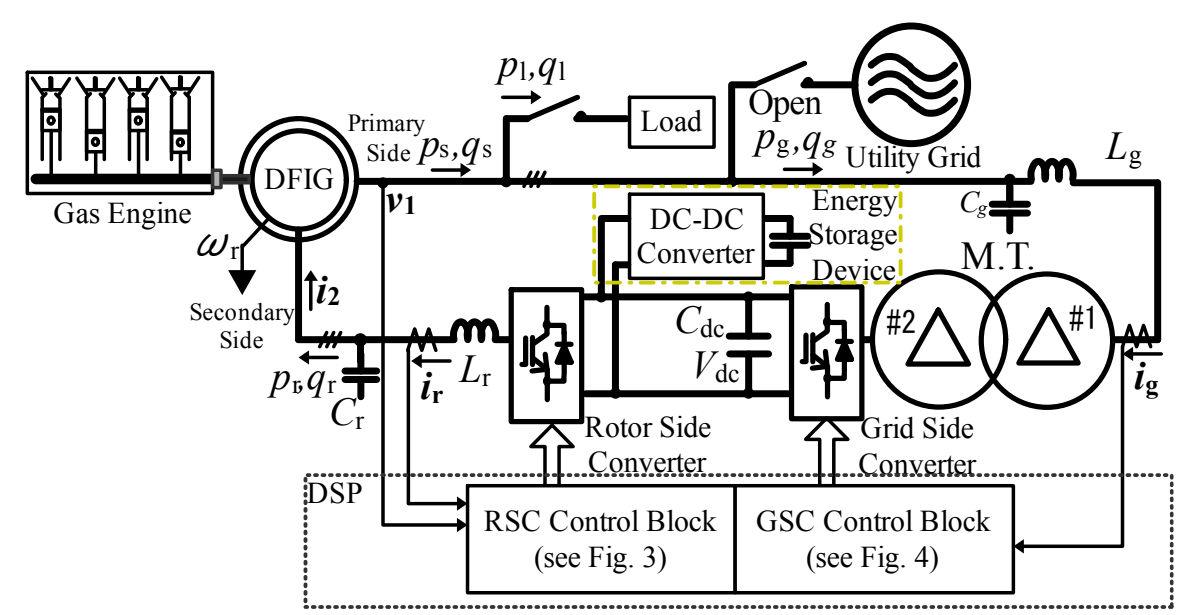

Fig. 2. Schematic diagram of the main circuit.

Employment of an adjustable speed generator can effectively solve the above-mentioned problems, such as the efficiency deterioration in part-load condition. Therefore, we have investigated the application of a doubly-fed induction generator (DFIG) to the gas engine cogeneration system as one of the ways to enable the gas engine to operate at adjustable speed regardless of grid frequency. An advantage of DFIG is to require less power converter capacity, which is only the maximum amount of the DFIG secondary side power depending on the operational speed range, compared with other adjustable speed $\mathrm{AC}$ generators that require the conversion of full output power. The adjustable speed operation makes the gas engine more efficient because of operations at optimal speed according to the load ratio (Fig. 1). Adjustable speed operation also enables the gas engine to operate temporarily in an overloaded condition. An increase in the amount of step load input during stand-alone operation is expected because the DFIG is prevented from causing the frequency excursion by controlling the secondary side frequency.

To operate during blackout as an emergency power supply is one of its important roles for the gas engine cogeneration system. A control scheme of the DFIG as an uninterruptible power supply function is studied in reference [2]. However, the DFIG requires initial excitation source for startup during blackout. In reference [3], two methods were described to provide initial power for the excitation. One method is to connect an energy storage to the DC link part at the DFIG secondary side through a diode. The other method is to utilize the remanence of the magnet circuit in the DFIG and additional AC stator capacitors. Initially, the DC link capacitor is charged when the DFIG operates as a squirrel-cage induction generator with shorted rotor circuit. Thereafter, the rotor circuit opens and a power converter provides excitation power with the charged DC link capacitor in order to generate the primary side voltage.

Loss analysis at the steady-state in a stand-alone generating

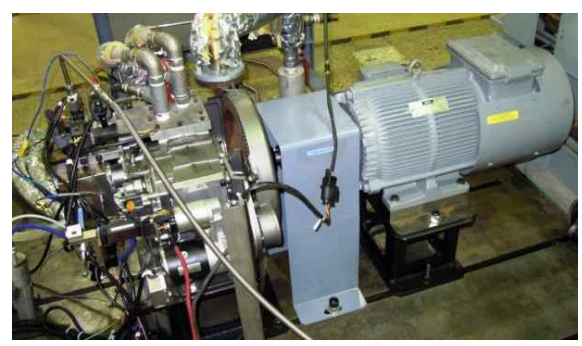

Fig. 3. Appearance of DFIG coupled with gas engine.

set with DFIG is important in terms of the efficiency of the generating set. Reference [4] presents a method to calculate various losses in the wind generating set in order to select an optimal generator for wind generation in terms of economic condition. In the reference, power converter losses, mechanical losses and DFIG internal losses were calculated based on the specification on the insulated-gate bipolar transistor module, the standard on electrical machine and the parameters of the DFIG whose rated power is $5 \mathrm{MW}$. However, all losses were derived from theoretical calculation.

In this paper, a charged capacitor has been installed in the DFIG secondary side for initial excitation. We have proposed a control method to provide the initial excitation power and to generate a rated voltage at the primary side during blackout [5]., which is called "blackout start" [5] in section II. In the case of For the experimental equipment, the secondary current becomes excessive when the DFIG is only excited from the secondary side to generate a rated voltage at the primary side. Exciting the DFIG from the primary side becomes necessary. We also shared the excitation current between the primary and secondary sides to suppress the secondary current.

Sections IV and V present the investigation on the stand-alone operation in applying and disconnecting loads after blackout start. We have used scale-down experiments with a real gas engine as the proposed control method of the blackout start. We have also demonstrated the stand-alone operation in which the excitation current is shared between the primary and 
TABLE I

CirCuit PARAMETERS

\begin{tabular}{|c|c||c|c|}
\hline$L_{\mathrm{r}}$ & $4 \mathrm{mH}$ & $L_{\mathrm{g}}$ & $4 \mathrm{mH}$ \\
\hline$C_{\mathrm{r}}$ & $10 \mu \mathrm{F}$ & $C_{\mathrm{g}}$ & $10 \mu \mathrm{F}$ \\
\hline$C_{\mathrm{dc}}$ & $11.8 \mathrm{mF}$ & \multicolumn{3}{|c}{} \\
\hline
\end{tabular}

TABLE II

DFIG PARAMETERS

\begin{tabular}{|c|c||c|c|}
\hline \multicolumn{2}{|c||}{ Rated } & \multicolumn{2}{c|}{ Parameter } \\
\hline Power & $1.1 \mathrm{~kW}$ & Stator resistance & $0.536 \Omega$ \\
\hline Frequency & $60 \mathrm{~Hz}$ & Rotor resistance & $2.377 \Omega$ \\
\hline $\begin{array}{c}\text { Number of } \\
\text { pole }\end{array}$ & 6 & $\begin{array}{c}\text { Leakage } \\
\text { reactance }\end{array}$ & $1.256 \Omega$ \\
\hline $\begin{array}{c}\text { Stator } \\
\text { voltage }\end{array}$ & $210 \mathrm{~V}$ & $\begin{array}{c}\text { Magnetizing } \\
\text { reactance }\end{array}$ & $26.99 \Omega$ \\
\hline $\begin{array}{c}\text { Stator } \\
\text { current }\end{array}$ & $6.3 \mathrm{~A}$ & Iron resistance & $3.658 \Omega$ \\
\hline $\begin{array}{c}\text { Rotor } \\
\text { voltage }\end{array}$ & $32.9 \mathrm{~V}$ & $\begin{array}{c}\text { Stator/rotor turn } \\
\text { ratio }\end{array}$ & 6.38 \\
\hline $\begin{array}{c}\text { Rotor } \\
\text { current }\end{array}$ & $20.3 \mathrm{~A}$ & \multicolumn{1}{|}{} \\
\hline
\end{tabular}

TABLE III

PARAMETERS OF MATCHING TRANSFORMER

\begin{tabular}{|c|c||c|c|}
\hline Phase & 3 & $\begin{array}{c}\text { Primary side } \\
\text { voltage }\end{array}$ & $460 \mathrm{~V}$ \\
\hline Capacity & $10 \mathrm{kVA}$ & $\begin{array}{c}\text { Secondary side } \\
\text { voltage }\end{array}$ & $230 \mathrm{~V}$ \\
\hline Frequency & $60 \mathrm{~Hz}$ & $\begin{array}{c}\text { Primary side } \\
\text { current }\end{array}$ & $12.6 \mathrm{~A}$ \\
\hline Connection & Delta-Delta & $\begin{array}{c}\text { Secondary side } \\
\text { current }\end{array}$ & $25.2 \mathrm{~A}$ \\
\hline \% Impedance & $1.54 \%$ & $\begin{array}{c}\text { Magnetizing } \\
\text { current }\end{array}$ & $4.10 \%$ \\
\hline
\end{tabular}

secondary sides by using scale-down experiments.

Section V presents the experiments on the power that flows in stand-alone generating set at a steady state. Losses in the stand-alone operation depend on the amount of load, power factor of load, and rotational speed of the gas engine. Results suggest that the generating set has optimal speeds at which the entire system losses are minimized.

\section{CIRCUIT CONFIGURATION AND CONTROL SYSTEM}

\section{A. Circuit Configuration}

Fig. 2 shows the main circuit configuration of the proposed system. The vectors of the primary side voltage $\boldsymbol{v}_{\mathbf{1}}$, secondary side current $\boldsymbol{i}_{2}$, rotor side converter (RSC) output current $\boldsymbol{i}_{\mathrm{r}}$, and grid side converter (GSC) input current transformed by a matching transformer (M.T.) $\boldsymbol{i}_{\mathrm{g}}$ are indicated in Fig. 2. The configuration can be defined as follows: $\boldsymbol{v}_{\mathbf{1}}=\left(v_{\mathrm{la}}, v_{\mathrm{lb}}, v_{\mathrm{lc}}\right), \boldsymbol{i}_{\mathbf{2}}=$ $\left(i_{2 \mathrm{a}}, i_{2 \mathrm{~b}}, i_{2 \mathrm{c}}\right), \boldsymbol{i}_{\mathrm{r}}=\left(i_{\mathrm{ra}}, i_{\mathrm{rb}}, i_{\mathrm{rc}}\right), \boldsymbol{i}_{\mathrm{g}}=\left(i_{\mathrm{ga}}, i_{\mathrm{gb}}, i_{\mathrm{gc}}\right)$. Fig. 3 shows that the DFIG was directly coupled with a gas engine. The gas engine, which was converted from a general-purpose diesel engine (producted by Yanmar, type: NFAD6), is used in the experiment. Two power converters are installed between the
DFIG primary and secondary sides with a common DC link. The converters are called RSC and GSC, which function as AC to AC power conversion. LC low-pass filters (LPFs) are connected to each AC output side of the converter. The filters reduce voltage and current ripples generated by each converter, enhance stator voltage quality, and are designed to consider both grid-tied and stand-alone operations. The load and utility grid are connected to the DFIG primary side. In this study, we assume that the DFIG is disconnected from the utility grid due to blackout. An electrolytic capacitor $C_{\mathrm{dc}}$ that was initially charged by the energy storage device through a DC-DC converter was connected to the DC link for initial excitation. The M.T. is installed between the GSC and the DFIG primary side.

Tables I, II, and III, respectively, show the parameters of the main circuit, the DFIG, and the M.T.

\section{B. Control System}

A RSC block diagram is shown in Fig. 4. The RSC controls the primary side voltage and frequency. The superscript * indicates a reference value. The control system employs proportional and integral (PI) control. The transfer function $G_{\mathrm{PI}}(s)$ is defined as follows:

$$
G_{\mathrm{PI}}(s)=K\left(1+\frac{1}{s \tau}\right),
$$

where $K$ and $\tau$ represent a gain and an integral time constant, respectively.

The phase of the RSC output current is represented in $\theta_{\text {slip }}$ and is calculated by $\int\left(\omega^{*}{ }_{1}-\omega_{\mathrm{r}}\right) d t$, where $\omega^{*}{ }_{1}$ is a reference of the output electrical angular speed, which is given by $2 \pi \times f_{0}$ $\mathrm{rad} / \mathrm{s}$. The value of $f_{0}$ is $60 \mathrm{~Hz}$ in this study. The DFIG electrical rotational speed $\omega_{\mathrm{r}}$ is obtained by a speed encoder. The root mean square (r.m.s) of the primary side line voltage is equal to $v_{1 \mathrm{dq}}$. The ripples on the voltage $v_{\mathrm{ldq}}$ are eliminated by a first-order LPF. Current control is used in the RSC control block diagram on the basis of the $d q$ rotational coordinates with the reference of RSC $q$-axis output current $i_{\text {rq }}^{*}=0$.

Fig. 5 shows a GSC control block diagram. The GSC controls both the DC link voltage to keep it constant and the reactive current $i_{\mathrm{gq}}$ to supply the excitation current from the primary side.

A phase locked loop (PLL) block diagram is shown in Fig. 6. The PLL acquires the phase angle of the primary side voltage $\theta_{1}$. The steady-state output frequency is represented by $f_{0}$. The primary side $q$-axis voltage is controlled to zero to align the $d$-axis with the primary side phase voltage.

The parameters of the PI controllers and LPFs are shown in Tables 4 and 5, respectively. The cutoff frequencies in Table IV are obtained from the closed loop transfer functions of the current control loops of the RSC and GSC. The frequencies indicated the current control response of the PWM inverters. PI 1, PI 3, and PI 5 are tuned by the cut-and-try approach. These closed-loop cutoff frequencies are not indicated because these frequencies do not represent the basic performances of converters. 


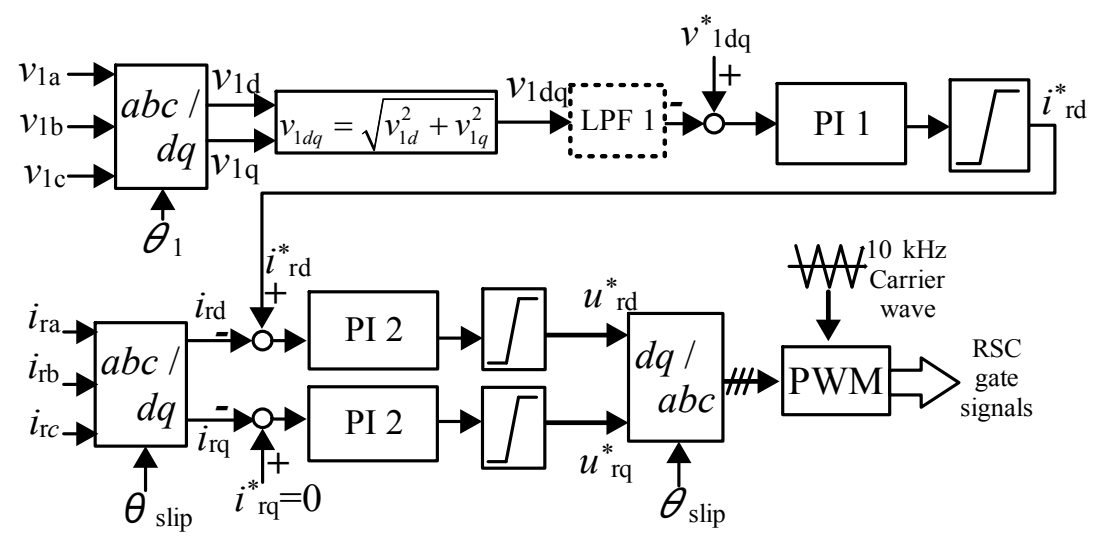

Fig. 4. RSC control block diagram.

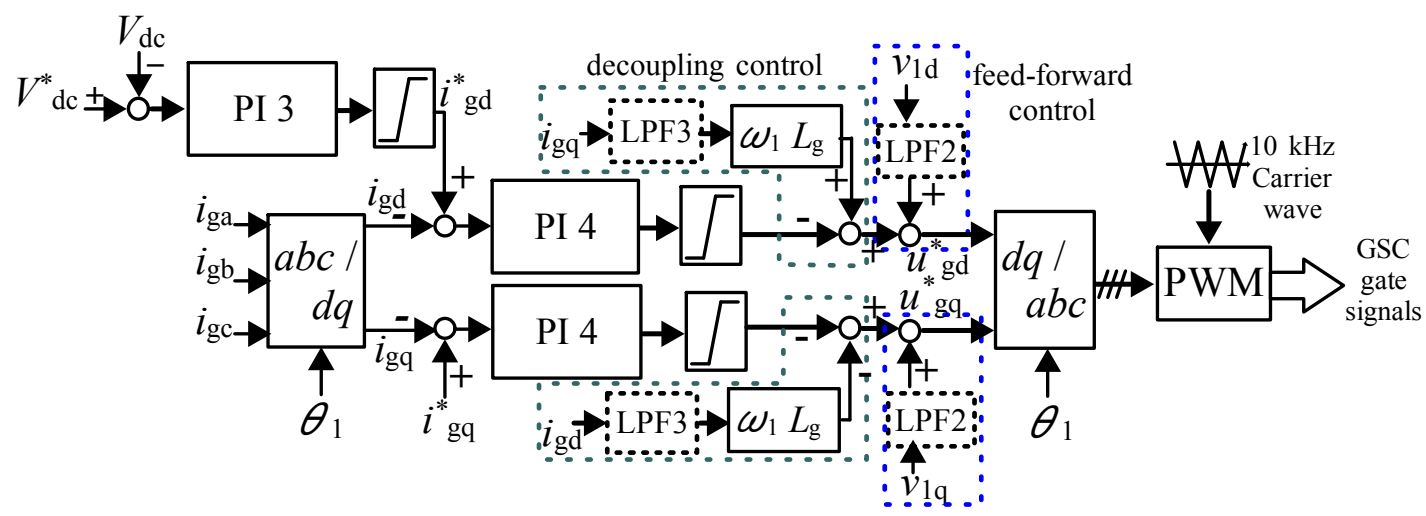

Fig. 5. GSC control block diagram.

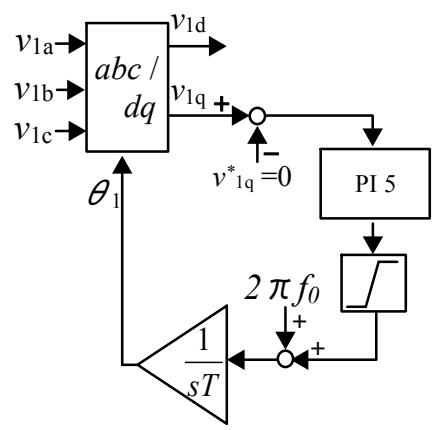

Fig. 6. Phase-locked loop block diagram.

The cutoff frequency of LPF 1 , which is placed after $v_{\text {ldq }}$ in Fig. 4, is determined to eliminate the $120 \mathrm{~Hz}$ ripple, which corresponds to the negative sequence component of the primary side voltage. The other LPFs placed at the feed-forward and decoupling control parts in the GSC current control are tuned by experiments so that the ripples on the primary side voltages and the GSC output current on the $d q$ rotational coordinates will not negatively affect the GSC current control.

The reference values used in the control blocks are summarized in Table VI.

\section{Sharing Excitation Current}

We tried to excite the DFIG only from the secondary side to generate the rated voltage at the primary side. However, the r.m.s. of the RSC output current is approximately 25 A (Fig. 7). Table II shows that the value exceeds the DFIG rated rotor current whose value is $20.3 \mathrm{~A}$ (see Table II).

Therefore, we shared the excitation current between the secondary and primary sides to suppress the RSC output current. On the basis of the no load test and the computer simulation results of the DFIG, we tentatively determine that the reference value of the excitation current from the primary side $i_{\mathrm{gq}}^{*}$ is $5 \mathrm{~A}$. Therefore, the GSC outputs 1 kvar (leading).

\section{Procedure of Blackout Start}

Fig. 8 shows the procedure for the blackout start. At the beginning of the blackout start, the gas engine is accelerated to a commanded speed. After reaching commanded speed, the RSC starts to operate and the DFIG is excited from the secondary side with electrolytic capacitor. The capacitor is charged by an energy storage device through a DC-DC 
TABLE IV

PI PARAMETERS

\begin{tabular}{|l|r|r|r|}
\hline & Gain & Time constant [s] & Cutoff frequency [Hz] \\
\hline PI 1 & 10 & 0.1 & \\
\hline PI 2 & 25.2 & 0.0597 & 1000 \\
\hline PI 3 & 0.05 & 0.05 & \\
\hline PI 4 & 25.2 & 0.0597 & 1000 \\
\hline PI 5 & 0.1 & 0.06 & \\
\hline
\end{tabular}

TABLE V

LPF PARAMETERS

\begin{tabular}{|l|r|r|}
\hline & Time constant[s] & Cutoff frequency[Hz] \\
\hline LPF1 & 0.01 & 15.9 \\
\hline LPF2 & 0.031 & 5.13 \\
\hline LPF3 & 0.031 & 5.13 \\
\hline
\end{tabular}

TABLE VI

REFERENCE VALUES

\begin{tabular}{|c|l||l|l|}
\hline$v^{*}{ }_{1 \mathrm{dq}}$ & $200 \mathrm{~V}$ & $i_{\mathrm{rq}}^{*}$ & $0 \mathrm{~A}$ \\
\hline$V^{*}{ }_{\mathrm{dc}}$ & $200 \mathrm{~V}$ & $i_{\mathrm{gq}}^{*}$ & $5 \mathrm{~A}$ \\
\hline
\end{tabular}
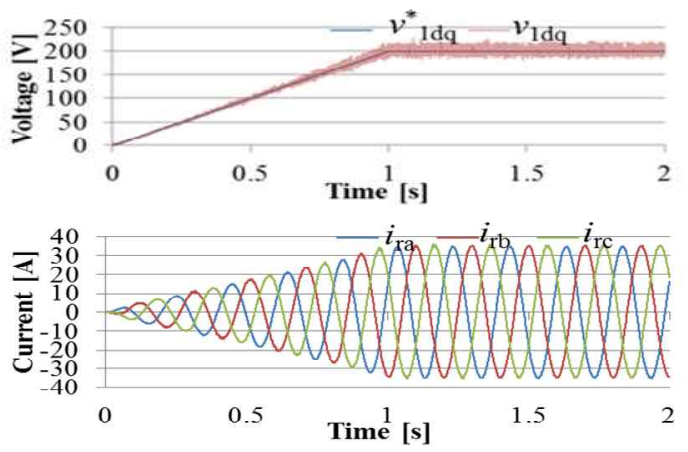

Fig. 7. Experimental waveforms of r.m.s value of the primary side line voltage $v_{1 \mathrm{dq}}$ and its reference $v_{1 \mathrm{dq}}^{*}$ (upper) and RSC output currents $\boldsymbol{i}_{\mathbf{r}}$ (lower) in the case of excitation only from the secondary side.

\begin{tabular}{c|c}
\hline Gas Engine & \multicolumn{1}{|c}{ DFIG } \\
\hline Stop & $\begin{array}{c}\text { Stop } \\
\text { Charge the de link capacitor } \\
\text { with energy storage device } \\
\text { Gradually generate the primary } \\
\text { side voltage by the secondary } \\
\text { side excitation using the RSC } \\
\text { The primary side excitation is } \\
\text { done by the GSC in addition to the } \\
\text { secondary side excitation. } \\
\text { Simultaneously, de link voltage is } \\
\text { controlled to constant by the GSC }\end{array}$ \\
Applyerate the rated voltage at the \\
primary side
\end{tabular}

Fig. 8. Procedure for the blackout start.

converter under no-loaded condition. The reference of the primary side voltage is gradually increased to avoid a sudden transient response. In the middle of generating the primary side voltage, the GSC starts to operate and the excitation current is fed by the primary side. Simultaneously, the GSC starts to control the DC link voltage to make the current constant. Thereafter, a rated voltage at the primary side is generated.

The application of loads is then available for the system.

\section{EXPERIMENTS OF BLACKOUT START}

We carried out experiments of the blackout start with the real gas engine.

\section{A. Experimental Condition}

The commanded values of the gas engine rotational speed were changed from $1000 \mathrm{rpm}$ to $1600 \mathrm{rpm}$ by $100 \mathrm{rpm}$ for each measurement. The experimental procedure is enumerated as follows:

1) Initially, the gas engine was driven to rotate at a commanded speed. The electrolytic capacitor was charged to $200 \mathrm{~V}$ by a DC voltage source. Thereafter, the voltage source was separated.

2) The control program started, and the RSC started to control $v_{1 \mathrm{dq}}$ to its reference value $v^{*}{ }_{1 \mathrm{dq}}$. The value was ramped up from $0 \mathrm{~V}$ to $200 \mathrm{~V}$ for $0.6 \mathrm{~s}$.

3) After $0.3 \mathrm{~s}$ from step 2, the GSC started to control the DC link voltage. The excitation current from the primary side was also controlled by the GSC $q$-axis current reference value $i_{\text {gq. }}^{*}$ The value was ramped up from $0 \mathrm{~A}$ to $5 \mathrm{~A}$ for $0.3 \mathrm{~s}$.

4) After $0.3 \mathrm{~s}$ from step 3, the blackout start was finished, and an application of loads was available.

\section{B. Experimental Results}

Fig. 9 shows the result of the proposed blackout start in the case of the initially rotating speed at $1300 \mathrm{rpm}$. The first and second dotted lines indicate the moment when the RSC and the GSC start to control, respectively. Results show that the primary side voltage was generated at a rated value. Fig. 10 shows the waveforms of the primary side voltage without load connection in an expanded time axis. A ripple on the DFIG rotational speed is shown in Fig. 9(h). The ripple was caused by the characteristics of the gas engine torque pulsation. A sudden drop in the rotational speed occurred at approximately $7 \mathrm{~s}$. The drop can be caused by the malfunctioning control system of the gas engine due to the light load condition. In spite of the speed ripple, the primary side voltage generated a constant value.

Fig. 9(c) shows that the RSC output current was greatly suppressed due to the excitation current shared between the primary and secondary sides. As shown in Fig. 7, the current was different from the excitation current that was provided only by RSC. 

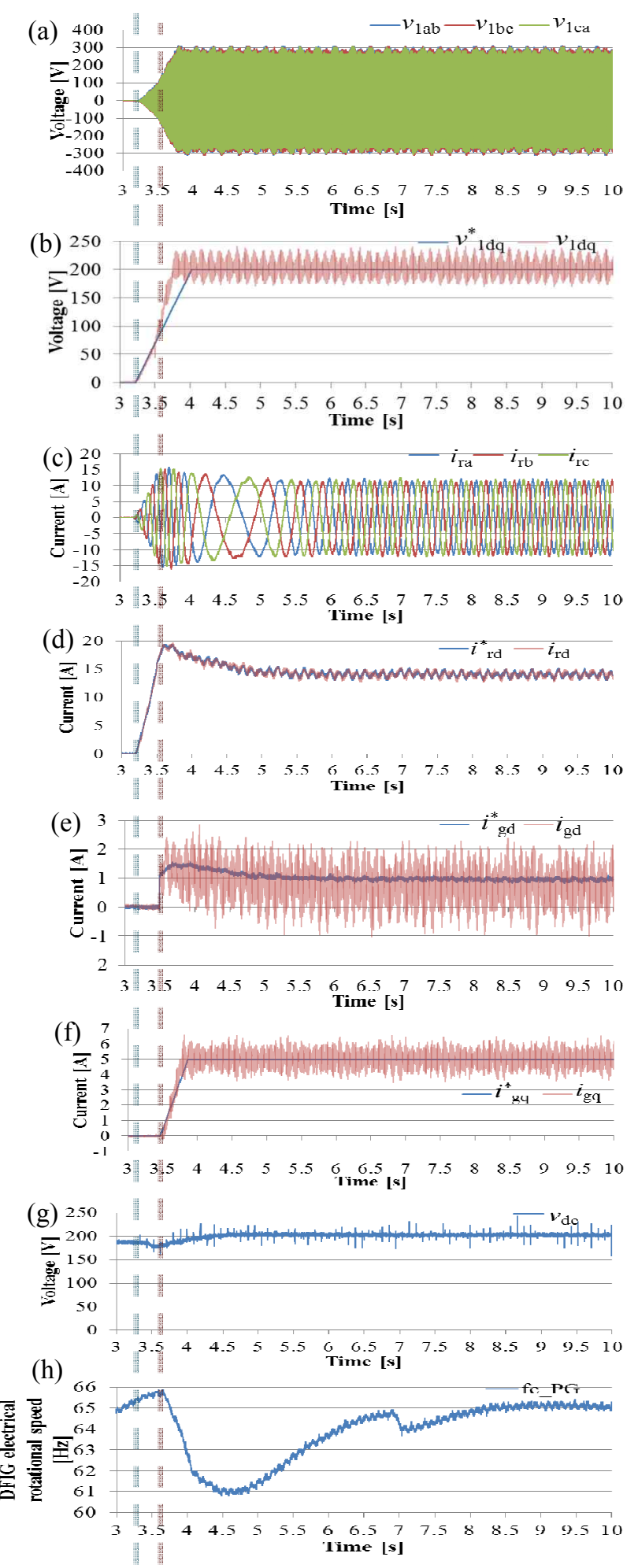

Fig. 9. Experimental waveforms of blackout start with real gas engine. (a) primary side line voltage $v_{\text {lab }}, v_{\text {lbc }}, v_{\text {lca }}$. (b) r.m.s. value of primary side line voltage $v_{1 \mathrm{dq}}$ and its reference $v^{*}{ }_{1 \mathrm{dq}}$. (c) RSC output current $i_{\mathrm{ra}}, i_{\mathrm{rb}}, i_{\mathrm{rc}}$. (d) RSC $d$-axis output current $i_{\mathrm{rd}}$ and its reference $i_{\text {rd. }}^{*}$. (e) GSC $d$-axis output current $i_{\text {gd }}$ and its reference $i_{\text {gd }}^{*}$. (f) GSC $q$-axis output current $i_{\mathrm{gq}}$ and its reference $i_{\mathrm{gq}}^{*}$. (g) DC link voltage. (h) DFIG electrical rotational speed.

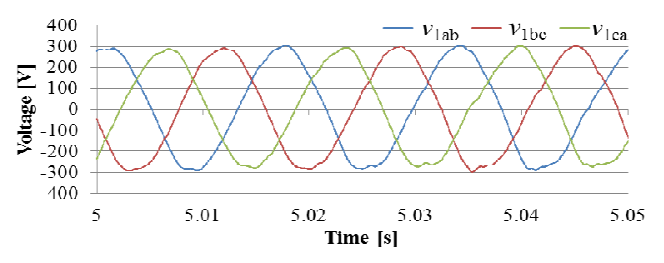

Fig. 10. Primary side line voltage during no load condition.

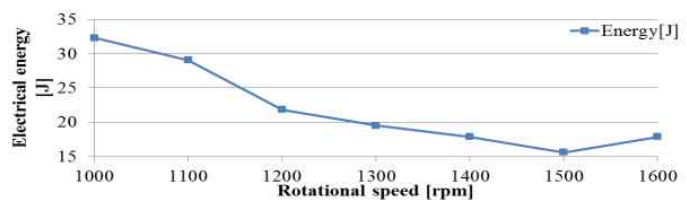

Fig. 11. Required energy for the initial excitation.

Fig. 11 indicates the required energy of the electrolytic capacitor for blackout start according to the commanded rotational speed. Energy was derived from the drop of the capacitor voltage during the blackout start. Results show that the required electrical energy for the initial excitation was less than $35 \mathrm{~J}$. Energy also depends on the commanded rotational speed. If the period of the blackout start becomes shorter, the required energy decreases. However, the primary side voltage overshot transitorily due to the voltage control response.

The initial excitation energy shown in Fig. 11 was consumed by iron loss, ohmic losses in DFIG windings, power converter losses, and LC filter losses. If the capacitor voltage largely decreases, the blackout start might fail because of the low voltage at the DC link.

\section{EXPERIMENTS OF STAND-ALONE OPERATION}

Application and disconnection of load under the stand-alone operation following the blackout start has been investigated. The reference of the rotational speed was $1300 \mathrm{rpm}$ in this study

\section{A. Application of Load}

Fig. 12 shows the waveforms of the load application. The amount of load was $200 \mathrm{~W}$ (power factor is unity). A dotted line indicates the moment when the load was applied. Figs. 12(a) and 12(c) show that the primary side voltage was controlled almost at a constant value by controlling the RSC output current. Fig. 12(h) shows the drop of the DFIG rotational speed when the load was applied. Approximately $5 \mathrm{~s}$ after the application of the load, the speed recovered to the commanded value. The frequency of the primary side voltage was obtained by detecting a zero crossing at the primary side phase voltage. The frequency was also filtered by 10 zero crossing point moving average because the voltage included some distortion. Regardless of the DFIG rotational speed, Figs. 12(b) and 12(h) 


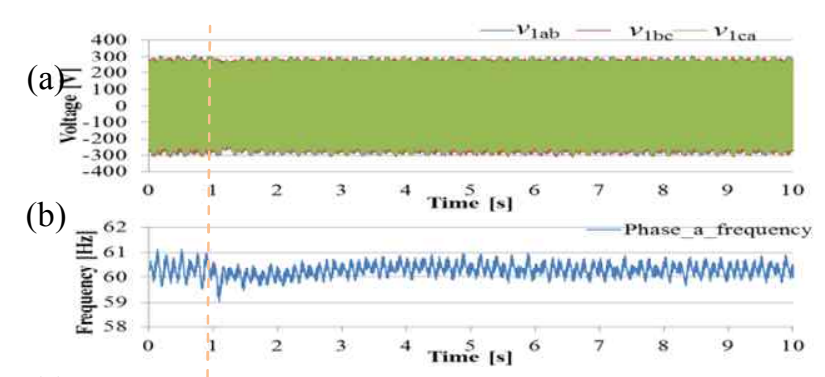

(c)

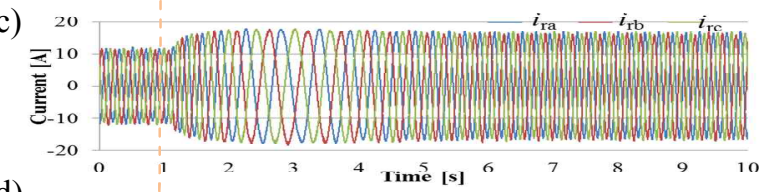

(d)

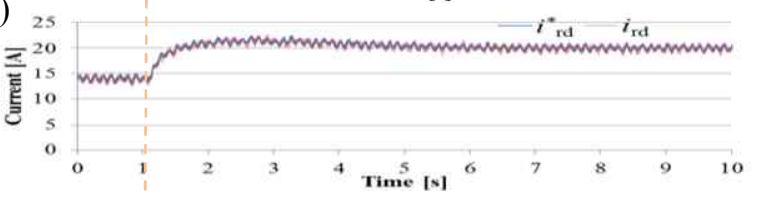

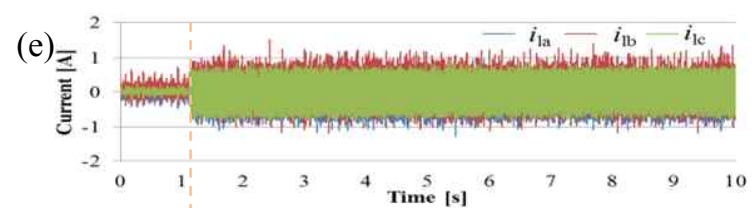
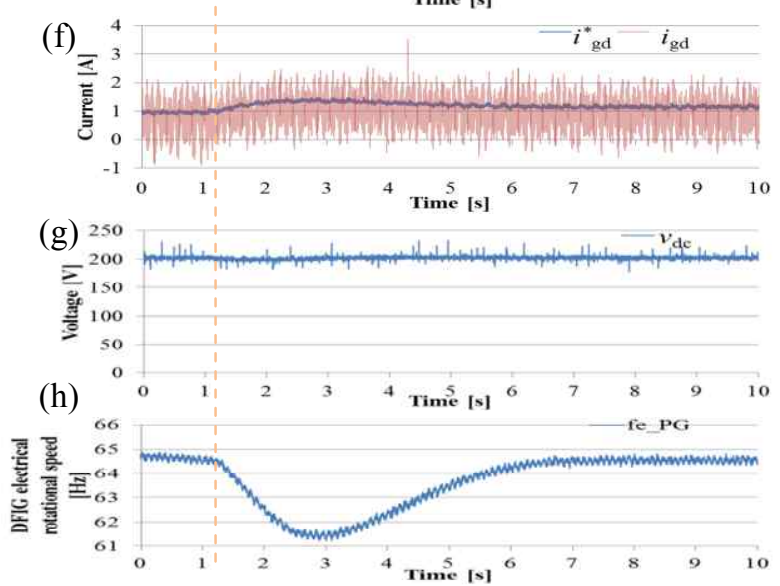

Fig. 12. Experimental waveforms of application of load. (a) primary side line voltage $v_{\text {lab }}, v_{1 \mathrm{bc}}, v_{\text {lca }}$. (b) frequency of primary side phase voltage. (c) RSC output current. (d) RSC $d$-axis output current $i_{\text {rd }}$ and its reference $i_{\text {rd. }}^{*}$ (e) load current $i_{\mathrm{la}}, i_{\mathrm{lb}}, i_{\mathrm{lc}}$. (f) GSC $d$-axis output current $i_{\text {gd }}$ and its reference $i_{\text {gd. }}^{*}$ (g) DC link voltage. (h) DFIG electrical rotational speed.

(a)

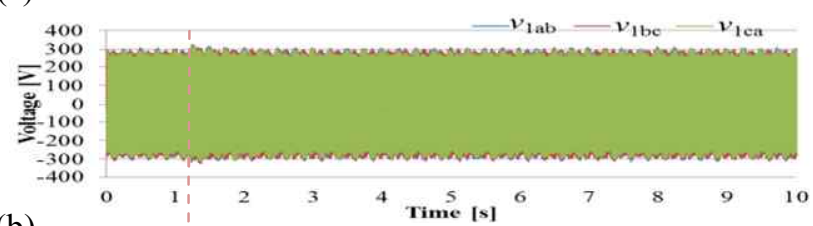

(b)

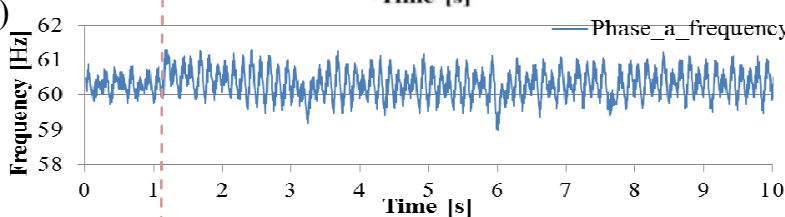

(c)

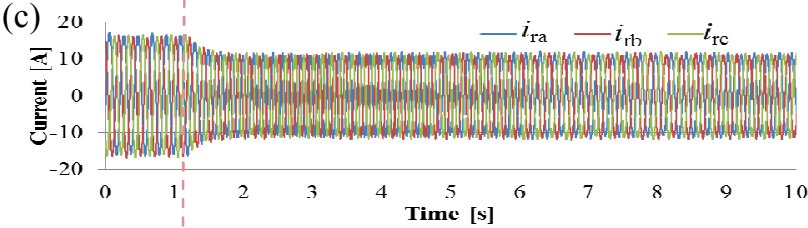

(d) 2

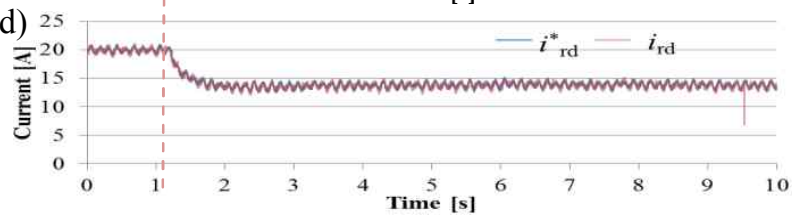

(e)

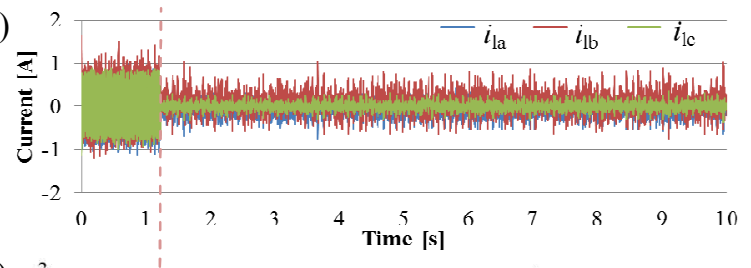

(f)
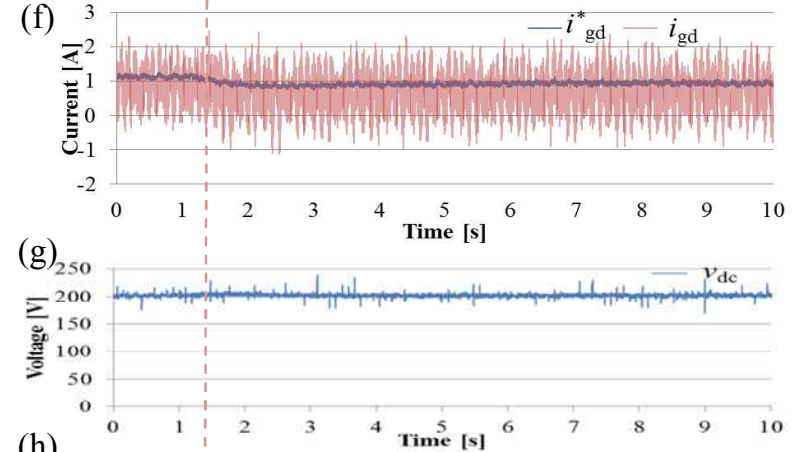

(h)

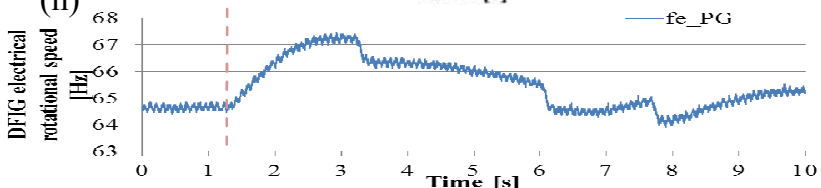

Fig. 13. Experimental waveforms of load disconnection. (a) primary side line voltage $v_{\text {lab }}, v_{1 \mathrm{bc}}, v_{1 \mathrm{ca}}$. (b) frequency of primary side phase voltage. (c) RSC output current. (d) RSC $d$-axis output current $i_{\mathrm{rd}}$ and its reference $i_{\text {rd }}^{*}$. (e)load current $i_{\mathrm{la}}, i_{\mathrm{lb}}, i_{\mathrm{lc}}$. (f) GSC $d$-axis output current $i_{\mathrm{gd}}$ and its reference $i_{\mathrm{gd}}^{*}$. (g) DC link voltage. (h) DFIG electrical rotational speed.

show that the frequency of the primary side voltage was kept almost constant regardless of the DFIG rotational speed. On the basis of the load currents, the RSC controlled the secondary side current frequency (see Figs. 12(c) and 12(e)). The current waveforms include high frequency components even if the load was not connected before $1.2 \mathrm{~s}$. The current sensors were greatly subjected to electromagnetic interference. Figs. 12(f) and $12(\mathrm{~g})$ show that the DC link voltage was controlled at constant by the GSC $d$-axis current. The $d$-axis current also includes high-frequency component due to the current ripple caused by the switching operation of the GSC. The validity of the proposed stand-alone control method was demonstrated by 


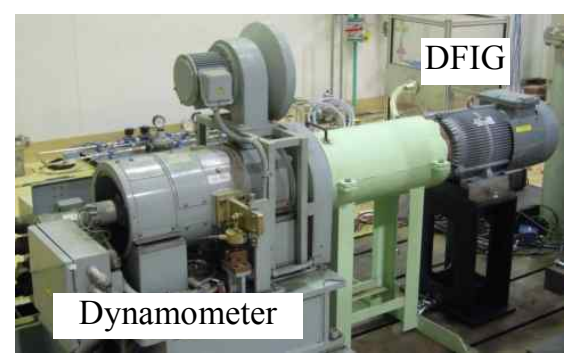

Fig. 14. Appearance of DFIG coupled with dynamometer.

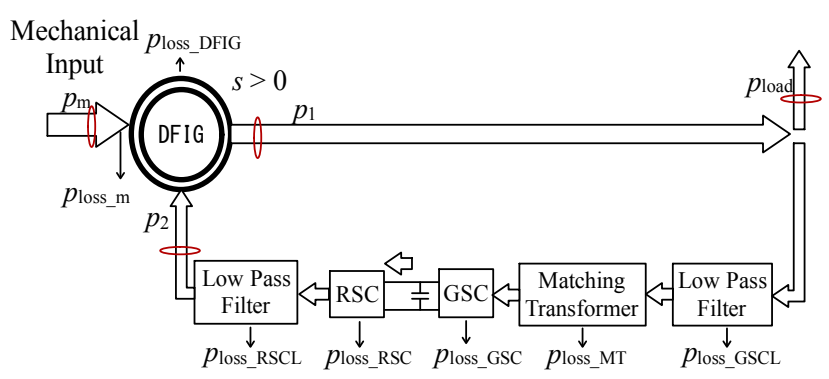

Fig. 15 Losses in DFIG generation system.

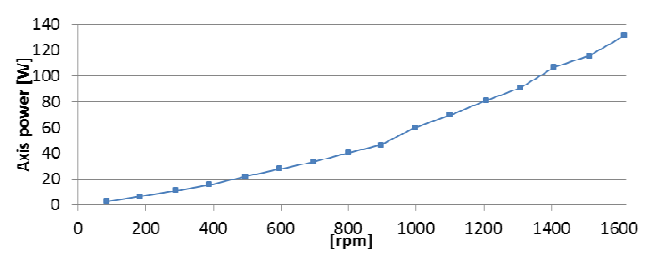

Fig. 16. Mechanical loss versus speed.

this experiment.

\section{B. Disconnection of Load}

The waveforms of disconnection of the load are shown in Fig. 13. The dotted line indicates the moment when $200 \mathrm{~W}$ (power factor is unity) load was disconnected. Fig. 13(h) shows the speed characteristics of the gas engine at the disconnection of the load. A sudden drop in the rotational speed after disconnection of the load occurred. The drop was caused by the light condition. As a result, the control system of the gas engine did not work appropriately. Regardless of speed variation, the primary side voltage was controlled to a constant value by the RSC. Fig. 13 shows that the disconnection of the load was successfully completed.

\section{EXPERIMENTAL RESUlTS OF POWER FLOW MEASUREMENT IN STAND-ALONE OPERATION}

We used experiments to investigate the power that flows in the generating sets with DFIG. A dynamometer (product by Ishito Electric Works Co., Ltd.) was used as a prime mover in order to measure the axis input torque of the DFIG. Fig. 14 shows the DFIG coupled with the dynamometer. The principle of the dynamometer was similar to a separately excited DC machine. In this experiment, the rotational speed was controlled.

The losses in the generating set are summarized in Fig. 15. Each loss from the generating set is defined as follows:

$p_{\text {loss } \mathrm{m}}$ : mechanical loss

$p_{\text {loss_RSC, }} p_{\text {loss_GSC }}$ : losses of RSC and GSC

$p_{\text {loss_RSCLC }}, p_{\text {loss_GSCLC: }}$ losses of LC filters at RSC and GSC ac outputs

$p_{\text {loss_MT: }}$ loss of matching transformer

$p_{\text {loss_DFIG }}$ : DFIG internal loss.

In Fig. 15, we measured the power that flows at four points as indicated by the red circle. A mechanical input was measured by the dynamometer. The primary side power, secondary side power, and load power were measured by POWER HiTESTER 3193 equipped with current sensor CT6862 (producted by HIOKI E. E. CORPORATION).

The generating set can be divided into three parts for loss investigation: (1) mechanical loss; (2) power conversion losses between the primary and secondary sides; (3) DFIG internal losses.

\section{A. Measurement of Mechanical Losses}

The mechanical losses were measured by opening the primary and secondary sides of the DFIG, idling at a commanded speed. Fig. 16 shows the results of the axis input power that corresponds to the mechanical losses. The mechanical losses are the total of the friction losses originated from the friction of axis, a bearing, and a brush. The windage losses originated from the wings for cooling and friction of other rotating parts against air. The mechanical losses were approximately proportional to the 1.6 power of the rotational speed.

\section{B. Experimental Results of the Power Flow Measurement in the Generating Set}

The power flows have been measured under no-loaded and loaded conditions in the stand-alone operation. The commanded speed was changed from $1000 \mathrm{rpm}$ to $1600 \mathrm{rpm}$ by $100 \mathrm{rpm}$. The following 11 types of loads were applied.

- no load

- 100 VA (P.F. were unity, 0.5 lagging and 0.5 leading)

- 200 VA (P.F. were unity, 0.5 lagging and 0.5 leading)

- 400 VA (P.F. were unity, 0.5 lagging and 0.5 leading)

- 600 VA (P.F. were unity)

The power flows and losses in the case of no-loaded and 400 VA loaded conditions are typical cases.

Figs. 17 and 18 show the r.m.s. values of voltage and current at the secondary side, respectively. The secondary side current decreased as the rotational speed increased. Fig. 19 shows the r.m.s value of the current at the primary side. Fig. 20 shows the relationship between the speed and DFIG axis input power 


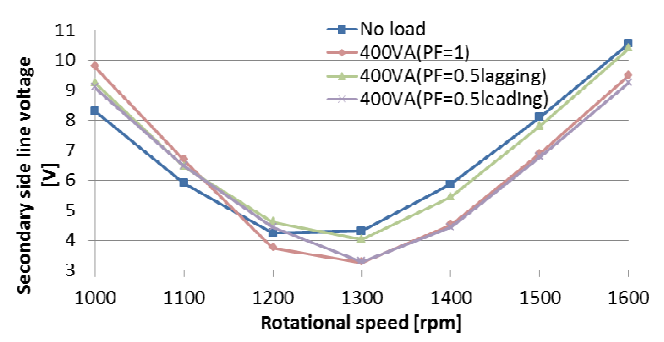

Fig. 17. Secondary side line voltage versus speed.

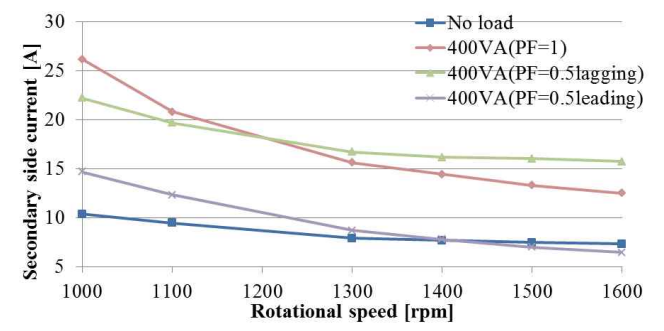

Fig. 18. Secondary side current versus speed.

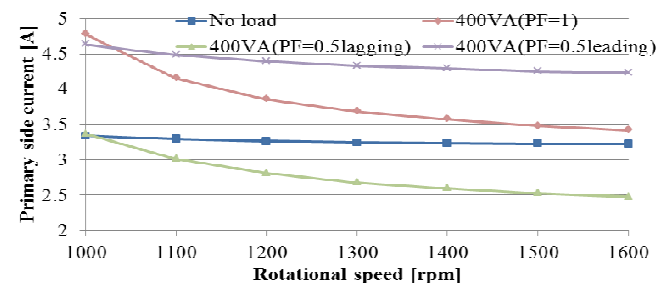

Fig. 19. Primary side current versus speed.

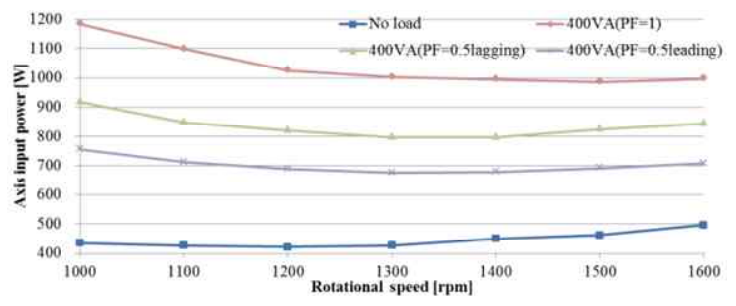

Fig. 20. DFIG axis input power versus speed.

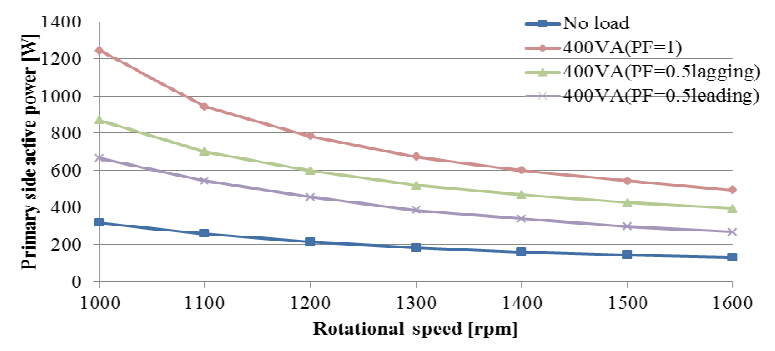

Fig. 21. Primary side output active power versus speed.

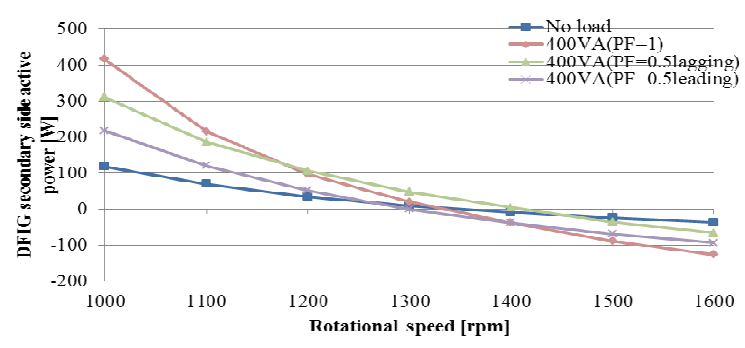

Fig. 22. Secondary side input active power versus speed.

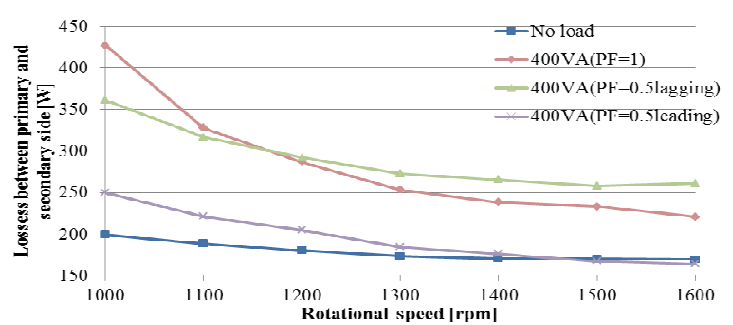

Fig. 23. Power conversion losses between primary and secondary sides versus speed.

measured by the dynamometer. Figs. 21 and 22 show the speed characteristics of the primary side output active power and secondary side input active power measured by HIOKI POWER HiTESTER, respectively. The relationship between the primary and secondary side active powers and the speed were theoretically considered in Appendix 1. Fig. A2 shows the neglect in the losses of the entire system. The values in Figs. 21 and 22 were larger than those in Fig. A2 when 400 W (P.F. was unity) was loaded. Fig. 21 shows that the primary side active power decreased as the rotational speed increased. As a result, the primary side current shown in Fig. 19 decreased. The secondary current shown in Fig. 18 decreased based on the law of equal ampere-turns as derived in Equation (A14) (see Appendix 1). Only the equal ampere-turns current decreased as the rotational speed increased. The secondary current in a $400 \mathrm{~W}$ (P.F. was unity) load greatly decreased compared with that of the 400 VA (P.F. is 0.5 lagging) load when the rotational speed increased. The active current of the load in the case of 400 VA (P.F was unity) load was larger than that in the case of 400 VA (P.F. is 0.5 lagging) load. Fig. 23 shows the power conversion losses between the primary and secondary sides. The power conversion losses were obtained by subtracting the sum of the load power and the secondary side input active power from the primary side output active power. In Fig. 23, the RSC losses and the LC filter account for the most part of the power conversion loss variation between the primary and secondary sides. The secondary side current shown in Fig. 16 had quite large variation compared with the primary side current. From the axis input power, the DFIG internal losses shown in Fig. 24 were obtained by subtracting the sum of the load power and the power conversion losses between the primary and secondary sides.

\section{Consideration of Optimal Speed in Various Load Condition}

The power flows in the generating set is expressed as follows:

$$
p_{\mathrm{m}}=p_{\text {load }}+p_{\text {loss_m }}+p_{\text {loss_conv }}+p_{\text {loss_DFIG }},
$$

where $p_{\text {loss conv }}$ is the power conversion losses between the primary and secondary sides. When the sum of $p_{\text {loss_m, }}, p_{\text {loss_conv }}$ and $p_{\text {loss DFIG }}$ become the smallest value according to speed, the speed is the most efficient rotational speed. Fig. 25 shows each optimal speed in various load condition, which is indicated by a dotted line. The figures show that the optimal speed varies 


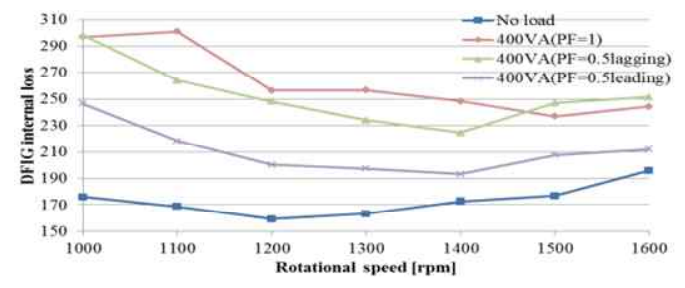

Fig. 24. DFIG internal loss versus speed.

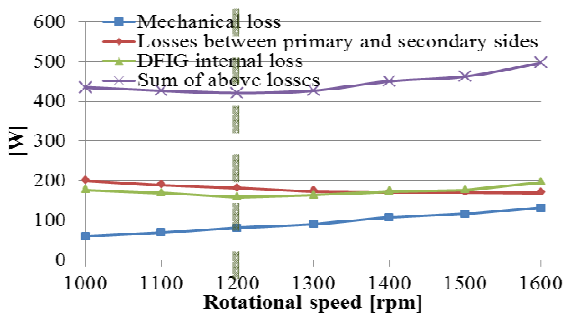

(a) No load

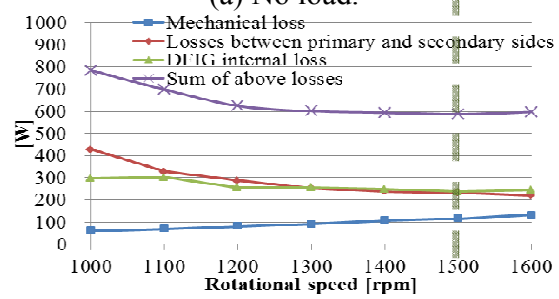

(b) 400 VA $(\mathrm{PF}=1)$ load.

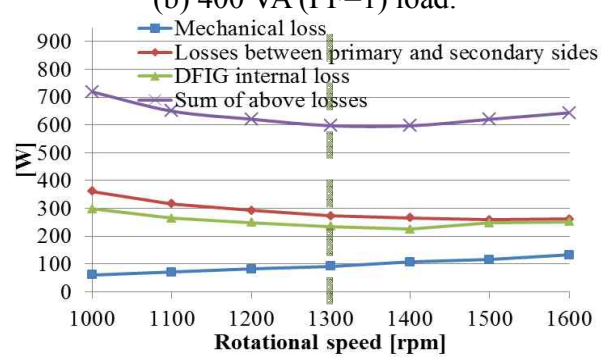

(c) $400 \mathrm{VA}(\mathrm{PF}=0.5$ lagging $)$ load.

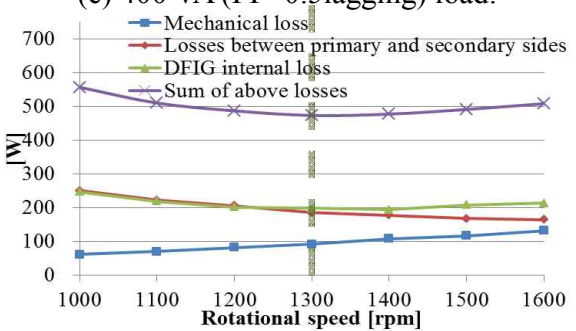

(d) $400 \mathrm{VA}$ ( $\mathrm{PF}=0.5$ leading) load.

Fig. 25. Losses in various load conditions.

with the amount and power factor of load. The power conversion losses between the primary and secondary sides vary depending on the load. Table VII shows the maximum efficiency and rotational speed of each load. When the losses of the entire generating set were minimized, the amount of increase in the mechanical loss exceeds the amount of decrease in the sum of the power conversion losses between the primary and secondary sides and the DFIG internal losses.

If the load active power becomes large, the power conversion losses between the primary and secondary sides
TABLE VII

MAXIMUM EFFICIENCY AND ITS RotATIONAL SPEED REGARDING EACH LOAD

\begin{tabular}{|l|c|c|}
\hline \multicolumn{1}{|c|}{ Load } & $\begin{array}{c}\text { Maximum } \\
\text { efficiency [\%] }\end{array}$ & $\begin{array}{c}\text { Rotational } \\
\text { speed [rpm] }\end{array}$ \\
\hline 400 VA $(\mathrm{PF}=1)$ & 40 & 1500 \\
\hline 400 VA ( $\mathrm{PF}=0.5$ lagging) & 25 & 1300 \\
\hline 400 VA ( $\mathrm{PF}=0.5$ leading) & 29 & 1300 \\
\hline
\end{tabular}

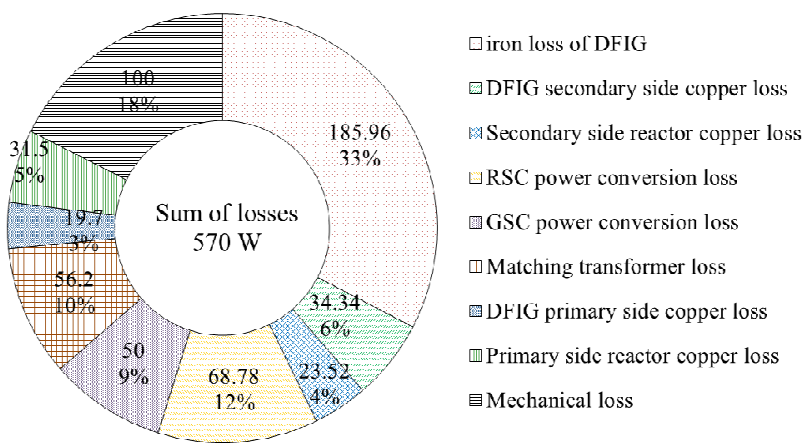

Fig. 26. Losses in the generating set rotating at $1500 \mathrm{rpm}$ and $400 \mathrm{~W}$ loading (P.F. is unity).

greatly increase compared with that in the case of light load. Therefore, the optimal speed tends to be higher in the case of heavy load.

In the practical field, the optimal speed can be determined when a DFIG outputs a rated output power. The optimal speed will become a steady-state operational speed.

\section{Discussion on the System Efficiency}

The efficiency of the generating set was derived from Fig. 25. When the generating set supplies $400 \mathrm{~W}$ (P.F. is unity) load and rotates at $1500 \mathrm{rpm}$, the efficiency of the generating set becomes the highest (Table 7). However, the efficiency is not more than $40 \%$ at the case. The low efficiency is mainly caused by three reasons.

First, the rated capacity of the DFIG used in the experiment was $1.1 \mathrm{~kW}$. The capacity is too small for practical use, which is assumed to be over $300 \mathrm{~kW}$. The no-load test of the DFIG shows that iron losses were approximately $200 \mathrm{~W}$ when the rated voltage was applied to the primary side. The small capacity of DFIG results in low efficiency.

Second, the generating set was not properly designed considering the whole system specifications. Given that the stator/rotor turn ratio shown in Table II is 6.38 , the secondary current becomes large. As a result, the secondary side losses increases, and the RSC losses occurred. The GSC was also used for the excitation from the primary side. Therefore, the losses in the GSC increased.

Third, mechanical losses are too large. When the rotational speed is $1500 \mathrm{rpm}$, the mechanical losses are $100 \mathrm{~W}$ (see Fig. 25). Mechanical losses such as windage loss and friction loss are relatively large compared with $1.1 \mathrm{~kW}$ of the DFIG rated 


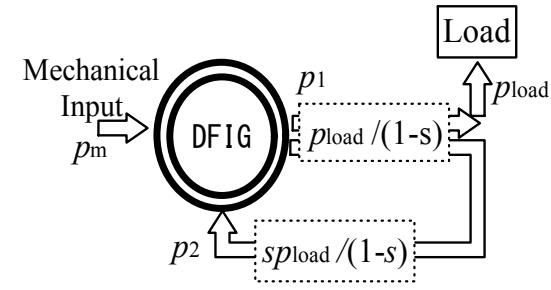

Fig. 27. Active power flow in the DFIG.

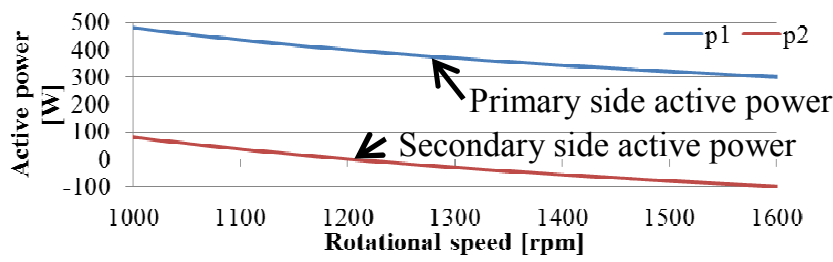

Fig. 28. Characteristics of active power versus rotational frequency $\left(p_{\text {load }}\right.$ is $\left.400 \mathrm{~W}\right)$.

power.

The details of losses in the generating set are summarized in Fig. 26 in the case of rotating at $1500 \mathrm{rpm}$ and $400 \mathrm{~W}$ loading (P.F. is unity).

In order to improve the efficiency of the generating set in practical use, two things are required.

- With a value of more than $300 \mathrm{~kW}$, the capacity of the experimental equipment should be converted into real scale capacity.

- The specifications of DFIG, power converters, and matching transformer should be optimally redesigned.

\section{CONCLUSION}

In this paper, the following results regarding the stand-alone operation are obtained.

1) A start-up method during a blackout of a doubly-fed induction generator applied to a gas engine cogeneration system has been proposed. A new initial excitation method of DFIG, sharing the excitation current between the DFIG primary and secondary sides, has also been proposed. The proposed blackout start has been verified by the experiment

2) The response of the primary side voltage control under load variation in a stand-alone operation has been investigated by an experiment. The amplitude and frequency of the primary side voltage are kept almost constant regardless of load variation.

3) The power that flows in the generating set with the DFIG has been experimented. Results show that the generating set has optimal rotational speeds at which the whole system losses are minimized. The whole system losses vary according to the amount of load, power factor of load, and rotational speed.

The DFIG applied to a gas engine cogeneration system improves the transient performance of emergency power supply, thus making the DFIG a promising alternative to a synchronous generator.

\section{APPENDIX}

\section{A. Theoretical Analysis on Power Flow in the Generating} Sets with the DFIG

The machine equations written in a synchronously rotating $d q$ reference frame are given as follows [6] (iron loss is neglected in the following equations):

$$
\begin{aligned}
\boldsymbol{v}_{\mathrm{s}} & =-R_{\mathrm{s}} \boldsymbol{i}_{\mathrm{s}}+\left(\mathrm{p}+j \omega_{\mathrm{s}}\right) \boldsymbol{\psi}_{\mathrm{s}} \\
& =-R_{\mathrm{s}} \boldsymbol{i}_{\mathrm{s}}+\left(\mathrm{p}+j \omega_{\mathrm{s}}\right)\left\{-l_{\mathrm{s}} \boldsymbol{i}_{\mathrm{s}}+M^{\prime}\left(-\boldsymbol{i}_{\mathrm{s}}+\boldsymbol{i}_{\mathrm{r}}^{\prime}\right)\right\}
\end{aligned}
$$

(A1)

$$
\begin{aligned}
\boldsymbol{v}_{\mathrm{r}}^{\prime} & =R_{\mathrm{r}}^{\prime} \boldsymbol{i}_{\mathrm{r}}^{\prime}+\left(\mathrm{p}+j \omega_{\mathrm{s}}\right) \boldsymbol{\psi}_{\mathrm{r}}^{\prime}-j \omega_{\mathrm{m}} \boldsymbol{\psi}_{\mathrm{r}}^{\prime} \\
& =R_{\mathrm{r}}^{\prime} \boldsymbol{i}_{\mathrm{r}}^{\prime}+\left(\mathrm{p}+j \omega_{\mathrm{s}}\right)\left\{l_{\mathrm{r}} \boldsymbol{i}_{\mathrm{r}}^{\prime}+M^{\prime}\left(-\boldsymbol{i}_{\mathrm{s}}+\boldsymbol{i}_{\mathrm{r}}^{\prime}\right)\right\}-j \omega_{\mathrm{m}}\left\{l_{\mathrm{r}} \boldsymbol{i}_{\mathrm{r}}^{\prime}+M^{\prime}\left(-\boldsymbol{i}_{\mathrm{s}}+\boldsymbol{i}_{\mathrm{r}}^{\prime}\right)\right\}
\end{aligned}
$$

)

where the symbols mean the following:

$\boldsymbol{v}_{\mathbf{s}}$ : space vector of the stator voltage in the $d q$ reference frame

$v_{\mathbf{r}}^{\prime}=a v_{\mathbf{r}}$ : space vector of the rotor voltage refers to the stator side in the $d q$ reference frame

$a=\frac{L_{\mathrm{s} 0}}{M}=\frac{M}{L_{\mathrm{r} 0}}:$ turn ratio of the stator to the rotor

$L_{\mathrm{s} 0}:$ stator self inductance

$L_{\mathrm{r} 0}$ : rotor self inductance

$M$ : mutual inductance between stator and rotor

$i_{\mathrm{s}}$ : space vector of the stator current in the $d q$ reference frame (a positive sign is the direction of flowing into DFIG)

$\boldsymbol{i}_{\mathrm{r}}{ }^{\prime}=\boldsymbol{i}_{\mathrm{r}} / a$ : space vector of the rotor current refers to the stator side in the $d q$ reference frame (a positive sign is the direction of the power flowing out of DFIG)

$M^{\prime}=L_{\mathrm{s} 0}=a M=a^{2} L_{\mathrm{r} 0}$ : mutual inductance refers to the primary side

$R_{\mathrm{s}}$ : resistance of the stator winding

$R_{\mathrm{r}}=a^{2} R_{\mathrm{r}}$ : resistance of the rotor winding refers to the stator side

$l_{\mathrm{s}}$ : stator leakage inductance

$l_{\mathrm{r}}=a^{2} l_{\mathrm{r}}$ : rotor leakage inductance refers to the stator side

$\omega_{\mathrm{s}}$ : synchronous angular speed in electrical angle

$\omega_{\mathrm{r}}$ : rotational angular speed in electrical angle $\mathrm{p}: d / d t$.

The terms of time derivative become zero in a steady-state. The following equations are derived:

$$
\begin{gathered}
\boldsymbol{v}_{\mathrm{s}}=-R_{\mathrm{s}} \boldsymbol{i}_{\mathrm{s}}+j \omega_{\mathrm{s}}\left\{-l_{\mathrm{s}} \boldsymbol{i}_{\mathrm{s}}+M^{\prime}\left(-\boldsymbol{i}_{\mathrm{s}}+\boldsymbol{i}_{\mathrm{r}}^{\prime}\right)\right\}, \\
\boldsymbol{v}_{\mathrm{r}}^{\prime}=R_{\mathrm{r}}^{\prime} \boldsymbol{i}_{\mathrm{r}}^{\prime}+j\left(\omega_{\mathrm{s}}-\omega_{\mathrm{m}}\right)\left\{l_{\mathrm{r}} \boldsymbol{i}_{\mathrm{r}}^{\prime}+M^{\prime}\left(-\boldsymbol{i}_{\mathrm{s}}+\boldsymbol{i}_{\mathrm{r}}^{\prime}\right)\right\} .
\end{gathered}
$$

When the resistance of the stator and rotor windings are neglected, an instantaneous output active power at the primary side $p_{1}$ is derived as follows:

$$
\begin{aligned}
p_{1} & =v_{\mathrm{sd}} i_{\mathrm{sd}}+v_{\mathrm{sq}} i_{\mathrm{sq}} \\
& =-\omega_{\mathrm{s}} M^{\prime}\left(i_{\mathrm{sd}} i_{\mathrm{rq}}^{\prime}-i_{\mathrm{sq}} i_{\mathrm{rd}}^{\prime}\right)
\end{aligned}
$$

Similarly, an instantaneous input active power at the secondary side $p_{2}$ is derived as follows: 


$$
\begin{aligned}
p_{2} & =v_{\mathrm{rd}} i_{\mathrm{rd}}+v_{\mathrm{rq}} i_{\mathrm{rq}} \\
& =-s \omega_{\mathrm{s}} M^{\prime}\left(i_{\mathrm{sd}} i_{\mathrm{rq}}^{\prime}-i_{\mathrm{sq}} i_{\mathrm{rd}}^{\prime}\right)
\end{aligned} .
$$

Equation (A6) divided by slip $s$ is equal to Equation (A5). The flowing equation is expressed as follows:

$$
p_{1}=\frac{1}{s} p_{2} \text {. }
$$

If all losses of the whole system can be neglected, mechanical input power is equal to load power. The mechanical input power can be expressed as

$$
p_{\mathrm{m}}=p_{\text {load }}=p_{1}-p_{2}=(1-s) p_{1}=\left(\frac{1-s}{s}\right) p_{2} .
$$

The primary and secondary side active powers are obtained as follows:

$$
\begin{aligned}
& p_{1}=\frac{1}{1-s} p_{\text {load }}, \\
& p_{2}=\frac{s}{1-s} p_{\text {load }} .
\end{aligned}
$$

Fig. 27 is obtained by Equations (A9) and (A10). Fig. 28 shows the characteristics of active powers versus the electrical rotational speed. The characteristics are obtained from Equations (A9) and (A10) when $p_{\text {load }}$ is $400 \mathrm{~W}$.

If the leakage inductances and the winding resistances of the DFIG are neglected, Equations (A3) and (A4) are derived as

$$
\begin{gathered}
\boldsymbol{v}_{\mathrm{s}}=j \omega_{\mathrm{s}} M^{\prime}\left(-\boldsymbol{i}_{\mathrm{s}}+\boldsymbol{i}_{\mathrm{r}}^{\prime}\right), \\
\boldsymbol{v}_{\mathrm{r}}^{\prime}=j\left(\omega_{\mathrm{s}}-\omega_{\mathrm{m}}\right) M^{\prime}\left(-\boldsymbol{i}_{\mathrm{s}}+\boldsymbol{i}_{\mathrm{r}}^{\prime}\right) .
\end{gathered}
$$

In order to keep the stator voltage constant, the current vectors $\left(-\boldsymbol{i}_{\mathrm{s}}+\boldsymbol{i}_{\mathrm{r}}\right)$ in Equation (A11) have to be constant. The current vectors are called excitation current and expressed as $\boldsymbol{i}_{\text {exc }}$. The stator and rotor currents are divided into the excitation current and an equal ampere-turns current. This relation is expressed as follows:

$$
\begin{aligned}
-i_{\mathrm{s}}+\dot{i}_{\mathrm{r}} & =\left(-i_{\mathrm{s}_{-} \mathrm{amp}}-i_{\mathrm{s}_{-} \mathrm{exc}}\right)+\left(i_{\mathrm{r}_{-} \mathrm{amp}}+\dot{\boldsymbol{i}}_{\mathrm{r}_{-} \mathrm{exc}}\right) \\
& =\left(-i_{\mathrm{s} \_\mathrm{amp}}+\dot{\boldsymbol{i}}_{\mathrm{r}_{-} \mathrm{amp}}\right)+\left(-\boldsymbol{i}_{\mathrm{s}_{-} \mathrm{exc}}+\dot{\boldsymbol{i}}_{\mathrm{r}_{-} \mathrm{exc}}\right) \\
& =0+\boldsymbol{i}_{\mathrm{exc}}=\boldsymbol{i}_{\mathrm{exc}},
\end{aligned}
$$

where the subscripts "amp" and "exc" mean equal ampere-turns current and excitation current, respectively. The equal ampere-turns currents have the following relation:

$$
i_{\text {s_amp }_{-}}=i_{\mathbf{r}_{-} \text {amp. }}
$$

Fig. 28 shows that the stator active power and primary side current decreased as the rotational speed increased. As a result, the secondary side current decreased due to the law of equal ampere-turns. In the experimental equipment, decrease in the secondary side current caused the decrease in copper losses at the secondary side. The copper losses of the rotor side converter and LC filter decreased as the rotational speed increased.

\section{REFERENCES}

[1] J. Lee, S. Lee, and S. Sul, "Variable-speed engine generator with supercapacitor: isolated power generation system and fuel efficiency," IEEE Trans. Ind. Appl., Vol. 45, No. 6, pp. 2130-2135, Nov./Dec. 2009.

[2] G. Iwanski and W. Koczara, "DFIG-based power generation system with UPS function for variable-speed applications," IEEE Trans. Ind. Electron., Vol. 55, No. 8, pp. 3047-3053, Aug. 2008.

[3] G. Iwanski and W. Koczara, "Control System of the variable speed autonomous doubly fed induction generator," European Power Electronics - Power Electronics and Motion Control - EPE-PEMC'04, pp. $72-80,2004$

[4] H. Ichita, R. Takahashi, T. Murata, and J. Tamura, "A study on the economic conditions of wind turbine generation system with doubly fed synchronous generator," IEEJ Trans. Industry Applications, Vol. 129, No. 11, pp. 1038-1047, Nov. 2009(in Japanese).

[5] T. Daido, Y. Miura, T. Ise, and Y. Sato, "A study on a start-up method during a blackout of a doubly-fed induction generator applied to gas engine cogeneration system," 8th Int. Conf. Power Electronics-ECCE Asia, pp.2051-2058, 2011.

[6] G. Abad, J. Lopez, M. Rodriguez, L. Marroyo, and G. Iwanski, Doubly Fed Induction Machine Modeling and Control for Wind Energy Generation Applications, Wiley-IEEE Press, 2011.

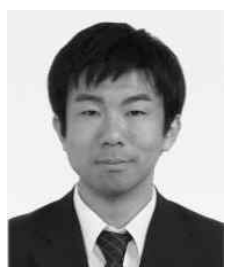

Tetsuji Daido was born in 1985 . He received his B.Eng. degree in electrical engineering from Osaka City University, Osaka, Japan. $\mathrm{He}$ also receieved an M.Eng. degree in electrical, electronic and information engineering from Osaka University, Osaka Japan in 2008 and 2010, respectively. He is currently working toward his $\mathrm{PhD}$ degree at the Graduate School of Engineering, Osaka University. His research interests include power electronics and distributed generation.

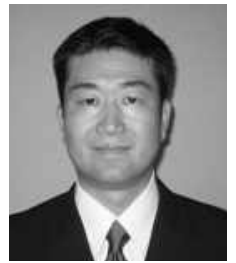

Yushi Miura received his $\mathrm{PhD}$ degree in Electrical and Electronic Engineering from Tokyo Institute of Technology, Tokyo, Japan, in 1995. From 1995 to 2004, he was a researcher at Japan Atomic Energy Research Institute. He developed power supplies and superconducting coils for nuclear fusion reactor. Since 2004, he has been an associate professor at the Division of Electrical, Electronic and Information Engineering, Graduate School of Engineering, Osaka University. His research interests include the application of power electronics and superconducting technology. He also researches on the control of distributed generations and energy storages in the power systems. 


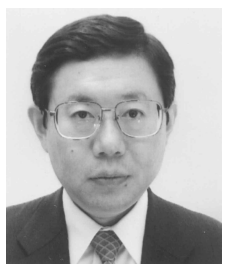

Toshifumi Ise was born in 1957. He received his B.Eng., M.Eng., and $\mathrm{PhD}$ degrees in electrical engineering from Osaka University, Osaka, Japan in 1980, 1982, and 1986, respectively. Since 1990, he has been with the Division of Electrical, Electronic, and Information Engineering, Graduate school of Engineering, Osaka University. From 1986 to 1990, he was with the Nara National College of Technology, Nara, Japan. He is currently a professor at the Osaka University. His research interests include power electronics and applied superconductivity including superconducting magnetic energy storages and new distribution systems.

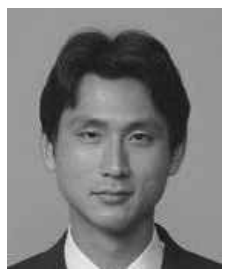

Yuki Sato was born in 1977. He received his B.Eng. and M.Eng. degrees in mechanical engineering from the Tokyo University, Tokyo, Japan in 1999 and 2001, respectively. Since 2001, he has been with the Energy Technology Laboratories of Osaka Gas Co., Ltd. 